\title{
Cervical Spine Discectomy, Osteo-facetectomy by Noble Art of Cloward Procedure and Its Modification- A Single Centre study
} AURANGZEB KALHORO, A. SATTAR M. HASHIM, ABID SALEEM

\author{
Neurospinal and Cancer Care Institute, Karachi-Pakistan
}

DOI: $10.36552 /$ pjns.v24i1.415

\section{ABSTRACT}

Objectives: To analyze the surgical outcome of cervical spine osteo-facetectomy discectomy, and modified Cloward procedure.

Materials and Methods: A prospective study was conducted at the Neurospinal \& cancer care institute, Karachi. The duration of study was from $1^{\text {st }}$ June 2017 to $25^{\text {th }}$ November 2019. Patients having prolapsed intervertebral cervical discs included in the study, while those with trauma, cervical radiation, previous cervical surgery and multiple level involvement were excluded. Pre and post-surgical data was collected. Titanium Hashmi cage was used in all operated patients at single level instrumentation.

Results: A total of 113 patients satisfied the inclusion criteria and were considered in the study. Among them, 77 patients were male and 36 were female. The age range from 26 to 65 with a base age of 53 years \pm 2.5 . C5 - C6 was the commonest level for fusion C6 -C7, C3-C4 and C4-C5 were less common. For the outcome of the procedure Odom's criteria, was followed the results showed excellent improvement in 88 (77.87\%), Good results in 18 (15.9\%), fair in $5(4.42 \%)$ and 2 patient had Poor (1.76\%) results. Fusion was seen in 86 patients, superficial infection in two cases.

Conclusion: Patients with single-level degenerative disc and treated with modified titanium Hashmi cage provided a good fusion with the relief of upper limb pain without donor site morbidity at anterior iliac spine.

Keywords: Cervical discectomy, Cloward procedure.

\section{INTRODUCTION}

Cervical spine degenerative disc disease patients presents with arm and neck pain, myelopathy, and radiculopathy that affects the daily life of patient. ${ }^{1}$ For a considerable period, Anterior Cervical Discectomy and Fusion (ACDF) is considered a gold standard treatment for cervical diseases. ${ }^{2}$ This approach is applicable in the instance of being very well aware of the anatomy as well as identifying any factors that might cause any sort of issue respectively. ${ }^{3}$ Cloward's anterior interbody fusion is considered to be popular for spondylosis and cervical disc protrusion. The fusion is accordingly accomplished with a cylindrical bicortical dowel graft harvested from the anterior iliac crest, which helps in decompression of foramina and maintaining the intervertebral space to devour the neurological issues related to it. ${ }^{4}$ Cervical spondylotic myelopathy (CSM) is among the continuously progressing spinal cord disorder especially the aged population. Many operative procedures have been adopted for the treatment of CSM, with some conflicting results. Anterior Cervical Discectomy and Fusion (ACDF) has been a popular procedure. ${ }^{5}$ Anterior approach to cervical spine degeneration initially explained by Robinson Smith and Cloward, it was commonly performed with satisfactory short-term results. In terms of good outcome, some of the authors have reported degenerative changes with the disc spaces adjacent to the fused segment and lower clinical outcomes for a follow-up respectively. ${ }^{6}$ It is observed that Cage's techniques have the potential upper hand in restoring disc height, preventing collapse of graft, indirect decompression of foramina and fusion in lordosis, patient has benefit of single-site surgery, neither surgical pain nor complication of donor site, we used bone-in micro pieces from surgical 
site and placed in the cage for good fusion. ${ }^{7}$ For outcome measures, Odom's criteria assessed clinical outcomes that are dynamic flexion and the extension radiographs are used to stabilize and assess the fusion accordingly. ${ }^{8}$ Titanium cage has its benefits for maintaining disc height, helping graft to be at a place, plus fusion in the lordotic spine also, ${ }^{9}$ even the long term outcome is also good with low complications. ${ }^{10,11}$ The purpose of the presented study was to assess the possible influence of the evaluation technique on the outcome of the modified Cloward technique which is considered as a Cloward procedure (osteofacetectomy) in the degenerative cervical spine. After standard discectomy procedure osteophytes were removed, titanium Hashmi cage with bone pieces from vertebra was used, instead of the anterior iliac graft to reduce extra morbidity. The considered outcome has been determined by Visual Analogue Score (VAS) and Odom's criteria.

\section{MATERIALS AND METHODS}

\section{Study Design}

Prospective observational study.

\section{Place and Duration}

This potential study conducted in the Neurospinal \& Cancer Care Institute, Karachi, Pakistan dated from 1st June 2017 to 25 November 2019.

\section{Inclusion Criteria}

Single level involved disc radiculopathy of the degenerative cause, whereas, no benefit from conservative management, the patient's consent was taken and it was approved from the hospital ethical review committee.

\section{Exclusion Criteria}

Exclusion criteria consider multiple level involvement, cervical pathology considered with the variance of previously operated patients, traumatic cervical fracture, cervical radiation and congenital cervical fusion.

\section{Data Collection}

A complete history, relative clinical and neurological examination, X-ray cervical spine and MRI cervical spine were done and were documented as a record.

\section{Surgical Technique}

Patient lying supine with neck extended and gardener tong in place for cervical anterior interbody fusion. The decorative pattern of the titanium cage is such that the anatomy of the vertebral bodies and disc space need no specific shaping. After complete discectomy, osteophytes were removed; the uncus base is measured with a width gauge. The retractors, longitudinal ligaments helps the central reference line which is aligned with the mid-line of the vertebrae, with the help of the hook the depth was measured behind the posterior wall of the vertebral plates. These measurements of depth and width helped us to determine the appropriate template size, then Titanium Hashmi cage (Implant) was filled with micro pieces of bone from the site and placed with focused guidance of C-arm, distance from the posterior wall of the vertebral body is minimum of $1 \mathrm{~mm}$. The adapted implant holder is used to grip implant, it helps to locate in the disc axis and assist in maintaining contact with the anterior face of the vertebral body. The adjustment of the implant is done per operative and adjusts accordingly. The implant during the insertion can be positioned with the implant holder. Hemostasis is maintained, Drain is placed in situ, traction was released and the collar is applied postoperatively.

\section{Data Analysis}

For all patients, the cage with bone material from cervical bone autograft was used. All procedures were performed by experienced neurosurgeons with a similar team. The inpatient spine position was used under General Anesthesia. The surgical level was confirmed with $\mathrm{x}$-ray per operatively by image Intensifier, bone micro pieces were taken from the involved vertebra and were placed in the exact position under image control. A cervical collar was used for postoperative. We used Odom's criteria for our research.

Fusion was observed with flexion \& extension cervical $\mathrm{x}$-rays and $\leq 1 \mathrm{~mm}$ movement at the required site was considered as fused in the following months. Outcomes also measured using a neck and arm pain and visual analog scale. SPSS version 20 was used for analysis. 


\section{RESULTS}

\section{Gender Incidence}

Total of 113 patients fulfilled, the criteria (inclusion) included in our study, among 77 patients were males and 36 were females.

\section{Age Incidence}

The age range was from 26 to 65 with an average age of 53 years \pm 2.5 . Gender distribution is shown in the table 1 below:

Table 1: Distribution of Gender.

\begin{tabular}{|l|c|c|}
\hline Gender & Number of Patient & Percent \\
\hline Male & 77 & $68.14 \%$ \\
\hline Female & 36 & $31.85 \%$ \\
\hline Total & 113 & \\
\hline
\end{tabular}

Table 2: Involved Vertebra - Vertebral Level.

\begin{tabular}{|l|c|c|}
\hline Disc Level & Number of Patients & Percentage \\
\hline C3-C4 & 2 & $1.76 \%$ \\
\hline C4-C5 & 12 & $10.61 \%$ \\
\hline C5-C6 & 67 & $59.29 \%$ \\
\hline C6-C7 & 29 & $25.66 \%$ \\
\hline C7-T1 & 3 & $2.65 \%$ \\
\hline
\end{tabular}

\section{Outcome}

We used Odom's criteria to calculate the results of the procedure. Operating time was 75 -minutes.

Results were Excellent in 88 (77.87\%), Good results in $18(15.9 \%)$. Average in $5(4.42 \%)$ and 2 patients had Poor $(1.76 \%)$ results. Fusion was seen in $86(76 \%)$ patients.

\section{Complications}

Superficial infection in two cases both were female.

Table 3: Frequencies of the Outcome.

\begin{tabular}{|l|c|c|}
\hline Outcome & No of Patient & Percentage \\
\hline Excellent & 88 & $77.87 \%$ \\
\hline Good & 18 & $15.9 \%$ \\
\hline Average & 5 & $4.4 \%$ \\
\hline Poor & 2 & $1.76 \%$ \\
\hline
\end{tabular}

\section{DISCUSSION}

The objective of putting grafted Hashmi cage into disc space is to have solid bone fusion and achieve alignment. Rough and corrugated edges of graft prevent graft dislodgement and graft collapse, decrease the need for external orthosis and hence the early return to activity. ${ }^{12,13}$

Noriega et al, had 28 patient they applied Odom's criteria had results presented with excellent in 17 patients $(60.8 \%)$, presented with good in $6(21.4 \%)$ outcome, fair in 5 had a (17.8\%) outcome in long term result. $^{14}$

In one of the studies, Heidecke et al, presented that considering short term outcomes in patients resulted to be around $92.9 \%$, which is considered good that is in 26 cases and $7.1 \%$ fair outcome that's 2 cases. If myelopathy sign symptoms were 1 year less it had a considerably better outcome ${ }^{15}$. As compared to our study comprising excellent results were noted to be 88 $(77.87 \%)$, good results in $18(15.9 \%)$, fair in $5(4.42 \%)$ and 2 patients had Poor (1.76\%).

In another study, Kaiser et al. used fusion with single-level anterior cervical discectomy in 157 cases with the use of plate and compared the results with a cohort of 242 non-plated patients. He found a fusion rate of $90 \%$ in non-instrumented patients and $96 \%$ inplated patients. ${ }^{16}$ We had a fusion rate of $86 \%$ with a 1-year follow-up.

Schröder et al, compiled 54 patients in the titanium group and 53 patients accordingly in the PMMA group. The radio imaging revealed relevantly better result from PMMA spacer than titanium group respectively. There is no comparative association formulated between fusion and clinical outcome that can be established between the fusion groups and the clinical outcome respectively. ${ }^{17}$ As compared to our study had an $86 \%$ fusion rate.

Kao et al. complications differed according to the material used. In autograft group, broken graft occurred in a similar number of patients, respectively (15.4\%) compared with the allograft group (3.4\%). In the allograft group, the complication rate was $13.8 \%$ (four of 29 patients), including one patient with a broken graft. In the autograft group, the complication rate was $26.9 \%$ (seven of 26 patients), including four patients with a broken graft, two patients with pseudarthrosis, and one patient with a hematoma and paresthesia at the donor site. In the cage group. ${ }^{18}$ In our study, there was a superficial infection in 2 cases, both were female while no cage was broken we used the Hashmi cage. 
Krishnan et al, took a large number of patients with long follow-up focused on a single level of C3-4 level with one year follow up having pharyngealtracheo-laryngeal complications were $20.3 \%$ in $32.4 \%$ of the difficult neck ${ }^{19}$ but in our center, no such injury was encountered.

Johnson et al, compared between rights and left side approach according to study but it's just dogma regarding right laryngeal nerve injury ${ }^{20}$ as in our setup all operations were performed from the left side of the neck approach.

Mohammed et al, reported that the most average operating level was C5 - C6 at in the single-level group, followed by C4 - C5 level in the single-level group, the single level group was approximately 71.5 minutes, while in the double-level group it was 110 minutes and in the hybrid group, it was 105 minutes $^{21}$ as in our study, the common level was same, while operating tine was similar around 75 minutes at a single level.

\section{CONCLUSION}

ACDF with the Hashmi cage is appropriate for the choice treatment in selected patients to maintain height, decrease pain and decrease need of a collar. In patients with single-level degenerative disc, modified Cloward procedure with titanium (Hashmi) cage provides good fusion and helps pain relief for cervical and arm pain it is considered as procedure of choice.

\section{REFERENCES}

1. Goffin J, Geusens E, Vantomme N, Quintens E, Waerzeggers Y, Depreitere B, Van Calenbergh F, van Loon J. Long-term follow-up after interbody fusion of the cervical spine. Clinical Spine Surgery, 2004; 17 (2): 79-85.

2. Zou S, Gao J, Xu B, Lu X, Han Y, Meng H. Anterior cervical discectomy and fusion (ACDF) versus cervical disc arthroplasty (CDA) for two contiguous levels cervical disc degenerative disease: a meta-analysis of randomized controlled trials. European Spine Journal, 2017; 26 (4): 985-97.

3. Fountas KN, Kapsalaki EZ, Nikolakakos LG, Smisson HF, Johnston KW, Grigorian AA, Lee GP, Robinson Jr. JS. Anterior cervical discectomy and fusion associated complications. Spine, 2007; 32 (21): 2310-7.

4. Faldini C, Pagkrati S, Leonetti D, Miscione MT, Giannini S. Sagittal segmental alignment as a predictor of adjacent-level degeneration after a Cloward procedure. Clinical Orthopaedics and Related Research®, 2011; 469 (3): 674-81.
5. Galasso $\mathrm{O}$, Mariconda $\mathrm{M}$, Iannò $\mathrm{B}$, De Gori $\mathrm{M}$, Gasparini G. Long-term follow-up results of the Cloward procedure for cervical spondylotic myelopathy. European Spine Journal, 2013; 1; 22 (1): 128-34.

6. Faldini C, Leonetti D, Nanni M, Di Martino A, Denaro L, Denaro V, Giannini S. Cervical disc herniation and cervical spondylosis surgically treated by Cloward procedure: a 10-year-minimum follow-up study. Journal of Orthopaedics and Traumatology, 2010 Jun. 1; 11 (2): 99-103.

7. Marbacher S, Hidalgo-Staub T, Kienzler J, WüerglerHauri C, Landolt H, Fandino J. Long-term outcome after adjacent two-level anterior cervical discectomy and fusion using stand-alone plasma sphere-covered titanium cages. Journal of Neurological Surgery Part A: Central European Neurosurgery, 2015;76 (03): 199204.

8. Thalgott JS, Xiongsheng C, Giuffre JM. Single-stage anterior cervical reconstruction with titanium mesh cages, local bone graft, and anterior plating. The Spine Journal, 2003; 1; 3 (4): 294-300.

9. Peolsson A, Vavruch L, Hedlund R. Long-term randomised comparison between a carbon fibre cage and the Cloward procedure in the cervical spine. European Spine Journal, 2007; 16 (2): 173-8.

10. Hermansen A, Hedlund R, Vavruch L, Peolsson A. A comparison between the carbon fiber cage and the Cloward procedure in cervical spine surgery: a ten-to thirteen-year follow-up of a prospective randomized study. Spine, 2011 May 20; 36 (12): 919-25.

11. Heidecke V, Rainov NG, Marx T, Burkert W. Outcome in Cloward anterior fusion for degenerative cervical spinal disease. Actaneurochirurgica. 2000; 1; 142 (3): 283-91.

12. Barnes B, Haid RW, Rodts G, Subach B, Kaiser M. Early results using the Atlantis anterior cervical plate system. Neurosurgical Focus, 2002 Jan. 1; 12 (1): 1-7.

13. Paramore CG, Dickman CA, Sonntag VK. A radiographic and clinical follow-up review of Caspar plates in 49 patients. Journal of Neurosurgery, 1996; 1; 84 (6): 957-61.

14. Noriega DC, Kreuger A, Brotat M, Ardura F, Hernandez R, Muñoz MF, Barrios C. Long-term outcome of the Cloward procedure for single-level cervical degenerative spondylosis. Clinical and radiological assessment after a 22-year mean follow-up. Actaneurochirurgica. 2013; 155 (12): 2339-44.

15. Heidecke V, Rainov NG, Marx T, Burkert W. Outcome in Cloward anterior fusion for degenerative cervical spinal disease. Actaneurochirurgica. 2000 Mar. 1; 142 (3): 283-91.

16. Kaiser MG, HaidJr RW, Subach BR, Barnes B, Rodts Jr. GE. Anterior cervical plating enhances arthrodesis after discectomy and fusion with cortical allograft. Neurosurgery, 2002; 50 (2): 229-38. 
17. Schröder J, Grosse-Dresselhaus F, Schul C, Wassmann H. PMMA versus titanium cage after anterior cervical discectomy-a prospective randomized trial. Zentralblattfür Neurochirurgie-Central European Neurosurgery, 2007; 68 (01): 2-7.

18. Kao FC, Niu CC, Chen LH, Lai PL, Chen WJ. Maintenance of interbody space in one-and two-level anterior cervical interbody fusion: comparison of the effectiveness of autograft, allograft, and cage. Clinical Orthopaedics and Related Research®, 2005; 430: 10816.

19. Krishnan SS, Nigam P, Manuel A, Vasudevan MC.
Modified high cervical approach for C3-4 anterior pathology in difficult neck patients. Journal of Craniovertebral Junction \& Spine, 2018; 9 (3): 182.

20. Johnson MD, Matur AV, Asghar F, Nasser R, Cheng JS, Prestigiacomo CJ. Right versus Left Approach to Anterior Cervical Discectomy and Fusion: An Anatomic versus Historic Debate. World Neurosurgery, 2019.

21. Mohammed H, Khalaf M, Farrah M. Evaluation of Different Modalities of Anterior Cervical Discectomy for Treatment of Single and Double Level Cervical Disc Herniation. J Neurol Neurosci. 2018; 9 (1): 246.

\section{Additional Information}

Disclosures: Authors report no conflict of interest.

Ethical Review Board Approval: The study was conformed to the ethicalreview board requirements.

Human Subjects: Consent was obtained by all patients/participants in this study.

Conflicts of Interest: In compliance with the ICMJE uniform disclosure form, all authors declare the following.

Financial Relationships: All authors have declared that they have no financial relationships at present or within the previous three years with any organizations that might have an interest in the submitted work.

Other Relationships: All authors have declared that there are no other relationships or activities that could appear to have influenced the submitted work.

Address for Correspondence:

Dr. Aurangzeb Kalhoro

Neurospinal and Cancer Care Institute, Karachi-Pakistan

Email: draurangzebkalhoro@gmail.com

\begin{tabular}{|l|l|l|l|l|}
\hline \multicolumn{5}{|c|}{ AUTHORSHIP AND CONTRIBUTION DECLARATION } \\
\hline Sr.\# & Author's Full Name & Intellectual/Contribution to Paper in Terms of: & Signature \\
\hline 1. & Aurangzeb Kalhoro & 1. & Proposed topics and Basic Study Design, methodology. \\
\hline 2. & A. Sattar M. Hashim & 2. & Data collection and calculations \\
\hline 3. & Abid Saleem & 3. & Analysis of data \& literature review \\
\hline
\end{tabular}

Date of Submission: 20-01-2020

Date of Revision: 03-03-2020

Date of Online Publishing: 31-03-2020

Date of Print: 31-03-2020 